\title{
MILITANTES NEGROS E O RACISMO NA MÍDIA SOTEROPOLITANA
}

\author{
BLACK ACTIVISTS AND RACISM \\ IN SALVADOR'S LOCAL MEDIA
}

\section{Tainan Silva da Purificação', Marilda Castelar²}

Autora para correspondência: Tainan Silva da Purificação - tatapurificacao@hotmail.com Psicóloga do Instituto Coração de Maria Unidade Barra do Jacuípe. Barra do Jacuípe, Bahia, Brasil. ${ }^{2}$ Psicóloga. Doutora em Psicologia Social. Professora na Escola Bahiana de Medicina e Saúde Pública. Salvador, Bahia, Brasil.

RESUMO I Na história da sociedade é notável a constante busca pelo avanço da tecnologia nos meios de comunicação, entretanto existem muitos questionamentos dos usos e comprometimentos dos mesmos em relação a produção e a difusão de preconceitos e estereótipos. Neste sentido, o objetivo geral desta pesquisa foi o de conhecer a opinião dos(as) militantes negros(as) sobre a imagem do(a) negro(a) que é transmitida pela mídia de Salvador- Ba. Os objetivos específicos foram de conhecer suas impressões e expectativas sobre sua própria imagem na mídia, seu papel como militante negro(a) e por fim investigar as estratégias de enfrentamento desses(as) militantes na luta contra o racismo na mídia de Salvador. Trata-se de pesquisa qualitativa na perspectiva Sócio histórica. Participaram da pesquisa seis pessoas, com idades entre 42 a 61 anos que se auto definiram como negros(as), militantes e que possuem visibilidade no contexto do movimento negro em Salvador. Foram realizadas entrevistas com roteiros semiestruturados, gravadas em áudio, transcritas e conferidas, conforme os procedimentos adotados pela História Oral. $O$ estudo dos relatos coletados baseou-se na análise de conteúdo e discurso. Foi possível conhecer a história do Movimento Negro em Salvador, a história de vida dos sujeitos e o processo de construção da visibilidade do movimento negro nas mídias soteropolitanas. Entretanto constatouse que a mídia local, permanece exibindo estereótipos e imagens negativas relacionadas ao negro. Neste sentido foi possível observar estratégias de luta em diferentes contextos, a partir dos relatos dos entrevistados, embora os mesmos não admitam a influência da mídia em suas vidas, aspectos que exigiram aprofundamento da presente pesquisa.

Palavras-chave: Psicologia; Racismo; Identidades; Militantes Negros; Mídia.

\begin{abstract}
In the history of society it is remarkable the constant search for communication technological advancements, however questions are raised as to the equivalent commitment when it comes to limiting the production and dissemination of prejudices and stereotypes. Thus, the objective of this research was to assess the opinion of (the) black civil rights activists on the portrayal of the black population by the media of Salvador-Ba. The specific objectives were to know their impressions and expectations about their own representation in the media, their role as black activists and finally to investigate the coping strategies of these activists in the fight against racism in the local media. It is a qualitative research from the socio-historical perspective. The participants were six people, aged 42-61 years, self defined as black activists and who have visibility in the context of the black civil rights movement in Salvador. Interviews were conducted with semi-structured scripts, audio-recorded, transcribed and checked in accordance with the procedures adopted by the Oral History. The study of the collected reports was based on content and speech analysis. It was possible to assess part of the history of the Black Movement in Salvador, aspects from the interviewed subjects' biographies and how the visibility of the black movement was built through their efforts in the local media. However it was found that the local media remains perpetuating stereotypes and negative representations related to black community. Counter strategies were observed in the subjects' reponses to the media inputs, although they themselves do not admit the influence of media in their lives. This contradiction requires futher investigation.
\end{abstract}

Key-words: Psychology; Racism; Identities; Black activists; Media. 


\section{INTRODUÇÃO}

A escolha de se conhecer e pesquisar as percepções do racismo na mídia por militantes negros(as) soteropolitanos(as) se deu devido ao lugar de poder que esse sujeito ocupa. $O(A)$ militante carrega em si a vontade da mudança de algum aspecto social que normalmente não é aceito pela sociedade, possibilitando a abertura de nova frente de estudos sobre o racismo e as representações das minorias políticas nas mídias.

Neste sentido, este trabalho teve como objetivo geral conhecer a opinião dos(as) militantes negros(as) sobre a imagem do(a) negro(a) que é transmitida pela mídia de Salvador, e como objetivos específicos o de conhecer suas impressões e expectativas sobre sua própria imagem na mídia em função do seu papel como militante negro e por fim investigar as estratégias de enfrentamento desses(as) militantes contra o racismo na mídia de Salvador-Ba.

A relevância deste trabalho está em abordar questões ligadas ao racismo e ao processo de construção da imagem midiática do Movimento Negro em Salvador. Para a psicologia é importante conhecer os mecanismos de reprodução e manutenção que a mídia utiliza para a construção dessa imagem e visibilidade dos(as) militantes do movimento negro atual, bem como os avanços, limitações e possibilidades. Além de contribuir na construção e desenvolvimento de estratégias para o enfrentamento do Movimento Negro diante do sofrimento psíquico causado pelo racismo veiculado pela mídia. Possibilitando o empoderamento dos sujeitos e o resgate da autoestima e da imagem positiva dos negros consigo mesmos.

Para este trabalho o termo Mídia foi considerado de acordo com Lima um "conjunto das emissoras de rádio e de televisão (aberta e paga), de jornais e de revistas, do cinema e das outras diversas instituições que utilizam recursos tecnológicos" para atingir os consumidores e espectadores. Incluiu-se aqui na atualidade as mídias digitais: portais, Websites, blogs, jornais e boletins online que transmitem notícias diferenciadas sobre os(as) negros(as). trabalho de homens e mulheres que se nomeiam militantes negros e que tiveram seu discurso e/ ou imagem veiculada pela mídia soteropolitana. Utilizamos as diretrizes da História Oral, pois através das memórias dos militantes negros, podese conhecer, e até mesmo realizar um paralelo entre a realidade vivida pelos participantes da pesquisa e a realidade midiática local atual. As entrevistas foram realizadas com o auxílio de gravação de áudio, posteriormente transcritas e analisadas, sendo esta a última etapa subsidiada pela análise de seu conteúdo, com o objetivo de perceber através de um olhar analítico as várias minúcias que engendram a fala dos entrevistados assim como os detalhes que se apresentam na formação do próprio discurso.

A compreensão da dinâmica e da influência midiática na formação da identidade se deu através dos discursos dos(as) militantes. Foi possível conhecer a história do Movimento Negro em Salvador, a história de vida dos(as) participantes e o processo de construção da visibilidade do movimento negro nas mídias soteropolitanas. Constatou-se que a mídia local, permanece exibindo estereótipos e imagens negativas relacionadas ao(s) negro(as). Neste sentido foi possível observar em estratégias de resposta a isto, com o intuito de empoderamento da comunidade subrepresentada através de ajustes nas representações que condigam com a realidade material, em diferentes contextos, a partir dos relatos dos entrevistados(as).

É preciso ampliar os estudos de psicologia sobre as formas em que o racismo está inserido tanto dentro dos espaços midiáticos quanto fora deles. A partir dos dados levantados as(os) profissionais de psicologia poderão entender e aprofundar 0 conhecimento sobre o fenômeno do racismo nas representações da mídia, a sua possível influência na formação da identidade individual e coletiva e algumas maneiras de enfrentamento contra este racismo.

Foram realizadas seis entrevistas nos locais de 


\section{PSICOLOGIA, MÍDIA E RACISMO}

O psicólogo inglês Francis Galton (1822-1911) foi um dos principais criadores da ciência da Eugenia, definida por ele como o estudo dos agentes sob o controle social que podem melhorar ou empobrecer as qualidades raciais das futuras gerações, seja física ou mentalmente. No Brasil, várias foram as tentativas de ações sociais que tinham a ideia da higiene racial como suporte, sobretudo no campo das ciências psicológicas, no início do século XX. Masieiro ilustra essas ações como: "A Sociedade Eugênica de São Paulo, que funcionou entre 1918 e 1920. A realização de Concursos de Eugenia, entre 1929 e 1932, em São Paulo, quando se procurou selecionar os 'exemplares raciais' brasileiros mais puros" (p.2). As características atribuídas aos brancos e negros do século XIX não mudaram, pois sempre foi designado ao negro um papel inferior em variados aspectos. Araujo afirma que "o desejo de branqueamento da nação, tornou-se convenção e naturalizou-se como estética audiovisual de todas as mídias, especialmente a TV, o cinema e a publicidade".

A televisão por possuir uma grande imersão no âmbito social, transmite a "ideologia do branqueamento" que segundo Bento é considerado como um problema do negro que, "descontente e desconfortável com sua condição de negro, procura identificar-se como branco, miscigenar-se com ele para diluir suas características raciais".

Diante de um olhar crítico, podemos observar que a influência estética televisiva atinge o sujeito diretamente na sua subjetividade, sua identidade. Ciampa concebe identidade como "um movimento, o desenvolvimento do concreto. É sermos o um e um outro, numa infindável transformação".

Entende-se que a construção da identidade dos sujeitos negros passa por constantes transformações. Podendo a mídia influenciar nesse processo de construção. D'adesky diz que "o espaço da mídia e da publicidade imprime, portanto, sua marca no processo identitário do negro por meio de uma imagem truncada que constitui, para ele, um modelo de inspiração negativo em termos de sedução sexual e estética".
Neste sentido, a mídia como meio eficiente de comunicação que utilizando-se da linguagem verbal e das imagens consegue transmitir aos(as) telespectadores(as) ○ que é conveniente. Ramos afirma que "signos e linguagem nos levam à percepção de uma sociedade permeada também pela presença de discursos". Portanto a sociedade utiliza-se desses discursos nas mídias para disseminar, as ideias racistas no imaginário popular.

Esta forma de comunicação é impactante em uma sociedade de pessoas não letradas com grande porcentagem de analfabetos que é em sua maioria de origem das culturas Africanas e Indígenas que não desenvolveram a escrita pelo não interesse dos colonizadores. Reafirmando o poder exercido por estes meios de comunicação no processo de dominação desses povos e de suas culturas.

No que diz respeito às práticas culturais e religiosas dos negros estas eram consideradas pela sociedade branca como imorais, selvagens e promíscuas e por isso os(as) negros(as) nunca se tornariam cidadãos civilizados. Evidenciando assim que o racismo já existia desde sempre na sociedade e era reproduzido nas páginas dos jornais impressos da mesma forma que na atualidade estas denominações povoam, por exemplo, as páginas policiais. Adotou-se o conceito de Munanga onde "o racismo é um comportamento, uma ação resultante da aversão, por vezes, do ódio, em relação a pessoas que possuem um pertencimento racial observável" por meio de sinais fenotípicos dos mesmos. No cotidiano, o racismo está presente na mídia de forma explícita ou sutil, basta uma observação crítica mais atenta para perceber o que Santos afirma que "a visão negativa sobre o negro emerge com toda a força quando à supremacia branca" (p30) e se sente ameaçada. Percebe-se por exemplo nos discursos de críticas às políticas de cotas aos(as) negros(as) que esta ameaça ainda é presente mesmo com toda garantia de direitos pelas leis vigentes no país. O racismo não só está presente na sociedade, como é refletido nas mídias se manifestando de forma estereotipada e equivocada tanto nas novelas com personagens de preto velho, mulatas, malandros, no cinema onde é representado como politizado, revolucionário, quanto na literatura aparecendo como sujeito preguiçoso, maldoso, sujo e na publicidade onde é exibida a sensualidade do corpo negro. Araújo corrobora quando diz que "os 
atores de origem negra e indígena serão escalados para representar os estereótipos da feiura, da subalternidade e da inferioridade racial e social, de acordo com a intensidade de suas marcas físicas e com o seu grau de mestiçagem". Para um melhor entendimento sobre esse assunto, será abordada um pouco da história do Movimento Negro e o surgimento da Imprensa Negra.

\section{O MOVIMENTO NEGRO E A IMPRENSA NEGRA}

No movimento de militância os "sujeitos" utilizaram maneiras para enfrentar o racismo, criando a imprensa negra que serviu como um recurso alternativo e independente de comunicação entre os militantes negros. Em 1798 foi organizada em Salvador a Revolta dos Búzios onde foram colados manifestos nas paredes da cidade, conforme publicado no jornal 'O Baiano', do jurista Antônio Pereira Rebouças (1828 a 1831). Barcelar afirma que na "década de 1931 foi fundada a Frente Negra Brasileira em São Paulo e em 1932 foi criada na Bahia". Frentes essas que não duraram por muito tempo, diminuindo a participação ativa dos negros na luta contra o racismo.

Nos momentos que o país respirou um pouco de democracia as lutas dos negros sempre reapareceram. Silva mostra alguns exemplo disso como os jornais: "O Jornegro de São Paulo, Tição do Rio Grande do Sul, e Nêgo, órgão informativo do MNU, como seus principais veículos de comunicação". Abdias do Nascimento fundou e dirigiu o Teatro Experimental do Negro (TEN) em 1944 no Rio de Janeiro, com o objetivo de ampliar o campo das artes cênicas para negros e negras. Já na década de 1960, ressurge no Brasil o Movimento Negro inspirado nas lutas antiapartheid e nos Panteras Negras entre outras manifestações contra o racismo pelo mundo, mudando totalmente 0 modo de atuação no país. Em 1964, quando instaurou-se a ditadura militar no contexto de repressão, continuou havendo resistência ao militarismo pela população negra. E em 1978 foi fundado o Movimento Negro Unificado (MNU) e neste sentido possui o papel de vanguarda nacional deste movimento.

Assim, desse processo histórico surgem participações marcantes de algumas pessoas, emergindo o "sujeito militante", que segundo Vinadé e Guareschi ao "identificar-se como militante tem forte ligação com a dimensão de entrar de cabeça na briga, como se o termo ganhasse sentido no suor da luta. Essa militância surge na vida das pessoas como uma via possível de exercer-se como sujeito, de ser o que se é".

Partindo dessa ideia considerou-se $\circ$ conceito de militância de Baltazar que compreende "a militância como uma forma de participação política engajada e crítica, na qual são desenvolvidas ações voltadas para a conscientização política da população, buscando desenvolver novos valores".

Apesar de todas estas mobilizações o racismo se manteve presente nos anos 80 e por isso as publicações de jornais em diversas capitais do país continuaram. Amaral colabora quando diz que "o racismo brasileiro é fruto de um olhar ocidental sobre 0 diferente, aqui especificamente sobre o negro. Se, por um lado, a elite de País exclui o negro do processo econômico, político e social, por outro, ela se quer Ocidental, e a mídia, instrumento mantenedor do status quo, também tem seu foco apontado para essa direção" (p.3).

As mídias se tornaram formadoras de opiniões, ideias e tendências, podendo influenciar na construção de identidades, imagens e discursos. Oliveira e Ronsini dizem que "no nível macro, a mídia assume o papel de gênero discursivo que pode estimular expressões políticas e institucionais acerca das relações interraciais".

Por este motivo não se pode abrir mão da presença dos(as) militantes negros(as) nos espaços midiáticos sociais, incluindo a internet, que possibilita a produção e perpetuação das informações facilitando a comunicação em rede no combate ao racismo. A AfroPress, uma agência Afro-étnica de notícias, fundada em 2004, utiliza a internet como meio de propagar suas reivindicações e propostas para superação do racismo.

A revista 'Raça Brasil', também surgiu como estratégia de quebra da invisibilidade dos negros. Ramos colabora com esta afirmação quando diz que "a publicação foi tida como responsável pelo reconhecimento do negro enquanto consumidor, recebendo a partir disso, maior atenção das 
indústrias e da mídia". Não se pode deixar de citar o Instituto Mídia Étnica da Bahia, criado desde 2005 com o slogan de 'denegrir a Mídia'. Cogo e Machado afirmam que "o Instituto mantém, ainda, o Insurreição Rítmica, uma rede de produção de vídeos comunitários em parceria com a TVE e com instituições e o portal de jornalismo colaborativo Correio Nagô". $\mathrm{Na}$ atualidade Alakija afirma que "A imprensa negra entra no século $X X I$ conservando o caráter original da não imparcialidade.Contrapondo-se á grande mídia,ela vem exercendo seu papel de cidadania na busca da dignidade humana e da convivência civilizada com as diferenças"

Além desses dispositivos, ○ Movimento Negro organizado, conseguiu por meio de diferentes pressões e ações frutos positivos por meio de organismos governamentais. Alguns exemplos podem ser citados, como a do Conselho Federal de Psicologia, que se considerou a Declaração Universal dos Direitos Humanos e toda a luta do Movimento Negro, para estabelecer normas de atuação dos(as) Profissionais de Psicologia em relação ao preconceito e discriminação racial. Foi criada a Resolução CFP Nº 18/2002. Outro avanço de extrema importância foi do Governo Federal ao estabelecer a Lei no 10.639, que inclui o ensino da História e da Cultura Afro-Brasileira nos currículos escolares.

Serão mencionados aspectos metodológicos empregados neste estudo para compreensão dos resultados encontrados.

\section{MÉTODOS}

O estudo enquadra-se em uma pesquisa qualitativa na perspectiva Sócio histórica segundo Freitas. De acordo com a autora "o sujeito se expressa, mas sua voz carrega $\circ$ tom de outras vozes, refletindo a realidade de seu grupo, gênero, etnia, classe, momento histórico e social". Também foi utilizada como recurso metodológico a História Oral, para Alberti "a consolidação da história oral como metodologia de pesquisa se deve ao fato de a subjetividade e a experiência individual passarem a ser valorizadas como componentes importantes para a compreensão do passado". Foram coletados relatos para conhecer, e até mesmo fazer um paralelo entre a realidade vivida pelos militantes negros no passado e a realidade midiática atual e abranger e diversificar os olhares tanto dos profissionais de psicologia quanto dos(as) próprios(as) militantes. Posteriormente foi executada uma análise de conteúdo e do discurso.

Os(as) participantes da pesquisa foram selecionadas através das redes de contatos, conforme (técnica utilizada pela História Oral), do Grupo de Trabalho Psicologia e Relações Raciais (GTPRR) do Conselho Regional de Psicologia da Bahia (CRPO3), do Grupo de Estudo Psicologia, Diversidade e Saúde, Linha: Memória, Cultura e Subjetividade da Escola Bahiana de Medicina e Saúde Pública (EBMSP). Como critério de seleção considerou-se as bandeiras de lutas, as manifestações públicas do Movimento Social, palestras em instituições diversas, as definições e exemplos práticos citados nos discursos dos militantes residentes em Salvador, que é a cidade com maior população negra do país. Participaram da pesquisa seis pessoas, sendo duas do sexo feminino (uma Jornalista e uma Atriz) e quatro do sexo masculino (um Advogado, um Economista, um Cientista Social e um Psicólogo) com idades entre 42 a 61 anos. Todos se auto definiram como negros(as), militantes e que possuem uma visibilidade no contexto do movimento negro em Salvador.

Como instrumento de coleta de dados foram utilizadas entrevistas com roteiros semiestruturados elaborados especificamente para cada participante, a partir de um roteiro geral de entrevista, onde se contemplavam questões sobre definição de racismo e de preconceito, opinião sobre a exposição do(a) negro(a) na mídia, opinião sobre o racismo na mídia de Salvador e relatar alguma situação vivida ou presenciada de racismo por eles. As entrevistas foram gravadas em áudio, transcritas, conferidas e também analisadas em seu conteúdo e discurso. A pesquisa foi aprovada pelo Comitê de Ética, Protocolo $\mathrm{n}^{\circ}$ 186/2011 (CAAE 33098814.0.0000.5544) e Ofício $n^{\circ} 31 / 2011$. Os(As) participantes assinaram o Termo de Consentimento Livre e Esclarecido (TCLE) e todos tiveram o sigilo nominal garantido. E todos tiveram o sigilo nominal garantido, a identificação 
foi codificada em: E1,E2, E3, E4, projeto de iniciação científica que recebeu uma bolsa da Fundação de Amparo à Pesquisa do Estado da Bahia - FAPESB.

\section{RESULTADOS E DISCUSSÃO}

Após a realização da revisão de literatura e das entrevistas, seguem os resultados de análise e discussão dos mesmos. Sem pretensão de se esgotar as possibilidades de aprofundamento acerca dos temas que compõem este estudo.

\section{Impressões sobre o racismo da mídia soteropolitana}

No discurso da entrevistada que segue abaixo e também na fala dos(as) demais entrevistados(as) evidenciou-se uma a percepção ou um reconhecimento da existência do racismo na imprensa soteropolitana.

"Eu estava assistindo um programa na Globo News, uma entrevista não sei o que[...] lá no meio assim de todas as entrevistas apareceu uma negona que era economista, no meio de tudo isso apareceu, chama logo atenção, eu aumentei para ouvir o que a mulher estava falando, porque é tão raro que quando você vê te chama a atenção, porra é uma negona sabe?

Aqui ela demonstra sua surpresa e orgulho ao se sentir mimamente representada por uma economista negra. "Então ainda a mídia é defeituosa, vamos usar esse termo, em relação ao povo negro". (E6,2012) Por outro lado, em seguida a entrevistada afirma que existe um defeito com a mídia, nesse discurso é constatada a falta de democracia nas suas exibições. Afirmando a invisibilidade dos(as) negros(as) neste veículo de comunicação.

Entre os seis entrevistados, a fala de E09 chama a atenção por ter sido o único em que a mídia aparece de forma menos negativa, seguindo a linha do "politicamente correto".

"A televisão hoje, a mídia é mais atenta quanto à questão racial. E é o politicamente correto, mas isso foi fruto do nosso trabalho, seria incompetência nossa. Então acho que hoje é diferente. Evidentemente que nem tudo são flores, ainda tem muita coisa que a gente questiona, mas mudou." (E5, 2012)

Vale salientar que este discurso pode ser um pouco diferenciado, pois a entrevistada faz uma certa defesa do espaço que ela ocupa, sendo a mídia o seu lugar de trabalho.

Então eventualmente as abordagens positivas são feitas num tom preocupante porque quase sempre são confinadas à área cultural, raramente se vê algo fora desse padrão. Há exceção tem se colocado pelo protagonismo de alguns jornalistas negros, que tem

conseguido uma manifestação muito elogiosa, se afirmando dentro de alguns órgãos e abrindo algumas frestas editorias, algumas pautas que anteriormente não existiam nesses órgãos." (E 1,2012)

Entretanto, é inegável que houve algum avanço com as conquistas do Movimento Negro a exemplo das legislações que vem garantindo um espaço, mesmo que mínimo na publicidade e nas mídias.

Já no discurso abaixo a mídia esta apenas cumprindo a lei da Constituição que assegura aos negros um lugar na mídia, segundo o entrevistado a mídia:

"Reproduz o racismo. Agora tá melhorando, tem algumas negras na televisão, em novelas, alguns negros em novelas, tá melhorando, mas não é ainda do tamanho que deveria ser. Nós somos $50 \%$ da população, então tem que ter $50 \%$ de atores, de apresentadores de telejornais, nada contra Fátima Bernardes, mas tem que ter mais negras nos telejornais de manhã, de tarde e de noite".

De fato a legislação, garante apenas $15 \%$ de cotas na TV e em imagens veiculadas pela mídia impressa, - entrevistado deixa registrado seu desejo de aumentar esta porcentagem.

Abaixo os entrevistados exemplificam $\circ$ racismo contido na mídia soteropolitana.

"Mas se você se refere aqui a mídia de um modo geral, eu vejo como negativa essas mídias que passam meio-dia, aqueles programas "Na Mira", "Bocão" e não sei o que, que só mostra negros e negras em situações desumanas, vulneráveis, de desrespeito profundo. Porque os traficantes ricos, os políticos que roubam, os empresários que não pagam impostos saem pela porta do fundo com 
aparato judicial, com advogado e o rosto coberto e os pretos pobres nego bota microfone na cara, mete a câmera, ainda faz piadinha e ainda manda cantar uma música para a mãe, ofereça uma música para a sua mãe, quer dizer isso é de uma perversidade terrível e às vezes

o cara é só suspeito, já está julgando". (E3, 2012)

"Olha, eu acho que é uma mídia muito racista, extremamente impermeável a uma política democrática de reaparecimento da diversidade, é uma mídia que reproduz uma visão bastante desfavorável sobre os negros, sobre a cultura negra. $E$ quando admite algo positivo, é num tom também de celebração reducionista.

$(E 1,2012)$

Os programas citados violam vários direitos do cidadão, eles são impróprios para o horário que é exibido, além de reforçarem estereótipos e preconceitos. Reafirmando Santos quando diz que a mídia produz um modelo negativo para os sujeitos negros.

Com relação a visibilidade do negro na mídia a Atriz e o Advogado trazem a ausência de jornalistas negros(as) na mídia (dentro de uma emissora da televisão) e a invisibilidade dos(as) negros(as).

"Você olha e não vê, você não se vê na televisão, você não se vê nas entrevistas e ninguém diz que é racismo, mas você sabe que é. Principalmente aqui em Salvador, é uma pena, mas em Salvador é terrível, assim eu vou voltar a TV Bahia que todo mundo assiste ou pelo menos boa parte da população assiste, cadê? Não tem e não

tem nenhuma preocupação de ter, não tem e acabou. Você não tem até quem apresente o jornal você olha bem, bem, bem, cadê?" (E6,2012)

Esta fala traz a invisibilidade dos sujeitos negros(as) como forma de racismo utilizada pela mídia soteropolitana pois é cultural e natural que as mídias reproduzam as ideias de quem dominam esses meios. O discurso abaixo reforça o que foi dito pela entrevistada acima.

"A mídia tem o papel de reafirmar historicamente a subalternidade, então a representação ora se dá pela invisibilidade, que é uma maneira de reafirmar a hierarquia e naturalizar a hegemonia racial branca, ora se dá por representação estereotipado que reforça os núcleos da subalternidade como expressão natural. Então a oscilação mais comum é entre esses dois polos: ou invisibilidade ou estereotipo". (E1, 2012)
Novamente é possível perceber que a mídia tem poder de dar visibilidade ao que é conveniente fato que interfere negativamente no imaginário coletivo, na auto estima e na subjetividade das pessoas negras.

\section{A influência da mídia na construção da identidade/ Auto imagem}

Neste item a fala do entrevistado Psicólogo se destaca dentre as outras porque traz uma teorização a respeito do processo da construção de identidade, deixando explícito o conceito formado por este sujeito através dos estudos sobre o assunto.

"Bem, toda a sociedade, toda produção cultural humana ela contribui para a nossa formação de identidade, por que a identidade nada mais é do que a construção do ser social, o ser individual que vai trabalhar em dois binômios: semelhança e diferença, esse duplo processo, duas vias de identificação, de diferenciar e de igualar, é o que ocorre dentro da construção de identidade, eu olho algo ou alguém e me vejo igual ou me vejo diferente então o que acontece? Quando eu me vejo igual eu começo a assumir, a incorporar os valores daquele grupo[...]tem uma serie de identidades que eu vou incorporando na base da semelhança e a diferença é aquilo que eu olho e digo não sou eu, só que existem também as coisas que você mesmo sendo, da representação tão negativa que é, você começa a dizer que não sou eu ou não quero ser isso e me afasto, então eu posso dizer que a mídia, ela com seus estigmas, seus estereótipos, suas representações do negro, ela faz com o que a nossa construção de identidade seja uma construção dolorosa" (E4,2012)

Destaca-se dentro deste discurso 0 processo de formação de identidade que contradiz o conceito utilizado neste trabalho por entender este processo por outras teorias, entretanto quando é trazido que a identidade passa pelo processo de formação onde é influenciada pela cultura humana que acaba sendo transmitida pelas mídias o tempo todo.

A afirmação abaixo da não influência da mídia na construção da identidade da militante ganha destaque pelo relato de que a família entrou como fator diferenciador

"Não. Eu aprendi lá dentro de casa com o vovô, com a minha vó, com os meus pais, meu pai, minha mãe, com a 
minha família.[...]Era assim, os negros do Amazonas são descendentes ou de barbadianas ou de Maranhenses. Eu

tive os dois lados na minha família, graças a Deus.[...] Mas o vovô tinha, então foi lá dentro de casa que a gente

se formou desde criança.[...] Então não foi na mídia, foi lá dentro de casa. Da mesma forma que nós educamos os nossos sobrinhos, dentro de casa, que são negros e tudo mais. A mídia abriu o meu olhar de como nós vivíamos em um país racista." (E5,2012)

Destacando que foi através da mídia que a mesma descobriu o racismo diferente dos outros entrevistados que já vivenciavam este fenômeno nos diversos espaços.

Com relação ao seu próprio discurso veiculado pela mídia o outro entrevistado afirma:

"Em geral, o que eu declaro com as adaptações editoriais que se impõem, tem sido veiculado. Não recordaria nenhum episodio em que eu tivesse sido deturpado, ou manipulado alguma declaração minha, não recordo.

Já tive várias situações de não ter publicado, de ser entrevistado e de não ser publicado, imaginado eu que o conteúdo coletado não interessava editorialmente, por razões políticas obviamente aos órgãos.[...]Então talvez esse tipo de interferência indireta possa ser identificada, mas distorção deliberada eu não recordo". (E 1,2012)

Na percepção desse entrevistado a mídia não distorce as falas do entrevistado porém como é formadora de opiniões, evidenciou-se que ainda há um controle das informações transmitidas para a população.

O discurso abaixo se destacou entre todas as entrevistas por que foi o único em que apareceu o reconhecimento positivo de autoimagem da militante na mídia soteropolitana.

"[..] Outro dia eu disse a uma colega minha assim, eu estabeleço códigos com a minha população com a minha negrada, com o meu povo.[...] ]eu sempre gostei de cabelo pixainha sempre achei legal, as pessoas chegarem assim com a filha e dizer olha você está vendo o cabelo

dela? Você podia deixar o seu cabelo assim. é uma marca, é uma referência, eu acho que mexe muito com a autoestima das pessoas mas a minha imagem é essa, eu sou isso. Eu sou isso a vida toda, eu fui educada, eu fui criada para ser o que eu sou para assumir o que eu sou para gostar de como eu sou. Eu acho que a mídia, a minha imagem é isso. Eu me vejo na mídia" (E5,2012)
Pela história de autoafirmação da identidade negra e consciência de pertencimento a uma comunidade, a militância foi aprendida e contribui para o fortalecimento da auto estima, abaixo ela traz um momento significativo da sua infância

"Eu aprendi desde criança isso, a vida toda, naquela época tinha uma revista chamada "Realidade" correspondia ao que seria hoje a revista "Veja", era a revista mais importante do país, [...] ]e tinha uma entrevista com Muhammad Ali Cassius Clay ir. aquele boxeador, então ele dizia "eu sou negro, eu sou bonito porque eu sou negro, eu sou o melhor", nós achavamos aquilo ali o máximo, mas a gente lia lia, eu sentava com meus irmão, eu sou a mais velha, a gente lia lia a entrevista toda, a gente achava fantástico aquilo ali, ele dizia que ele era negro, que ele era o mais bonito, que ele era o melhor, e nesse tempo não tinha televisão ainda". (E5,2012)

De modo geral percebeu-se no discurso dos entrevistados que a mídia soteropolitana é racista e segundo os mesmos não houve influência midiática na construção de identidade de nenhum deles, gerando a hipótese de que por serem todos militantes e que alguns por terem um espaço familiar de afirmações da identidade e consciência negra não se percebem influenciados pelas mídias.

A autoimagem dos(as) entrevistados(as) é positiva, se reconhecem na mídia, e consideram que seu discurso quando é transmitido não sofre nenhuma alteração, porém esse ponto necessita ser melhor investigado.

\section{Estratégias de enfrentamento contra o racismo}

Por fim buscou-se através de algumas falas analisar as estratégias que os(as) militantes utilizam e/ou Movimento Negro no combate ao racismo midiático.

No período de 1828 a 1831 já havia jornais que falavam de negros(as) para negros(as). Evidenciando que desde muito cedo os(as) negros(as) tentam diminuir as manifestações do racismo.

"Eu lembro que na década de 80 existia cartaz que dizia bem assim: Atenção senhores publicitários! Negro usa sabonete, pasta dental, calça jeans. Ai ia relacionando uma série de coisas. $E$ até tem carro. Isso na década de 80. Foi feita uma pesquisa dessa invisibilidade na época".

$(E 5,2012)$ 
O enfrentamento ao racismo iniciou-se no país na década de 1930 e foi ocupando diferentes âmbitos como culturais, religiosos e legislativos na luta contra o preconceito e a discriminação racial.

"O llê Ayiê mantém um programa de rádio chamado "Tambores da Liberdade" que é muito importante também. Há alguns anos atrás houve o "Black TV", na tentativa

de manter um programa com recorte étnico, que não sobreviveu muito tempo e há uma necessidade urgente de retomada. $E$ eu hoje participo junto com outros ativistas, intelectuais, de uma tentativa de viabilizar mais um órgão

de imprensa negro, para dar voz a essa dimensão da cidadania soteropolitana, que acaba quase sempre sendo silenciada". (E 1, 2012)

Apesar de todas essas iniciativas importantes na historia do Movimento Negro ainda é mínima a ocupação dos espaços midiáticos.

"O bando é uma companhia de teatro que existe há 22 anos com um trabalho respeitado, com um trabalho sério, um trabalho bem informado, bem embasado, a gente não faz nada sem embasamento, mas e tá na cidade esse tempo todo e enfim o grupo inteiro, que é uma coisa super rara, o grupo inteiro fazer parte de seriado de $t v$, onde o grupo todo vai, cada um claro com seus temas, mas o grupo inteiro. $O$ grupo inteiro é convidado para fazer um filme, dois filmes, metade do grupo é convidado

para fazer, tudo isso é muito interessante para teatro

baiano, companhia de teatro negra, nunca que a gente foi chamado para falar disso em Tv Bahia, nada, nunca e não tenho nada contra ninguém, adoro o pessoal da..não vou nem citar o nome". (E6,2012)

As falas dos entrevistados transcritas evidenciam um avanço da luta do Movimento e dos(as) próprios(as) militantes no combate ao racismo no século XXI.

"Hoje você tem que adotar estratégias e pensar. Como eu vou vincular isso, como eu vou vender isso? $E$ hoje é mais fácil. Mesmo até porque esse trabalho cresceu muito, são várias frentes de trabalhos. Não é só o Movimento Negro

Unificado, não é só o Olodum, são várias frentes de trabalhos. Frente de trabalho, eu entendo como grupo de samba, grupo afro, terreiro de candomblé, como grupo de mulheres, como associação de moradores, são frentes de trabalho que lutam contra racismo". (E5, 2012)

Abaixo o entrevistado cita especificamente uma mídia impressa. Identificando uma possível abertura desta via de comunicação para ele e o papel que ele representa.
“Eu já fui página do 'A Tarde' duas vezes, a página inteira do jornal. A Tarde que é "unimizerê"[é de destaque], é um histórico, nós colocamos na sexta depois do carnaval, a capa do jornal A Tarde falando de racismo, foram os dados do observatório da discriminação racial." (E2, 2012)

Já neste relato foi possível apontar alguns meios alternativos de comunicação do enfrentamento ao racismo

"[...]Nós temos construído alguma coisa, por exemplo o Instituto de Mídia Étnica com a proposta de "denegrir na mídia" que é o slogan, o chamado deles que eu acho bem interessante quando você vai construindo alternativas, tem

também o Correio Nagô, que são outras possibilidades de mídia com essa ideia das redes sociais e você vai

tendo outros canais e terminando pautando a mídia[...]

Eu diria assim a existência desses outros canais seja por blog, seja pelo face tem dado mais visibilidade a questão racial e levando esses conteúdos e isso não é só específico do Movimento Negro". (E,2012)

Apesar de todas essas iniciativas importantes na historia do Movimento Negro ainda é mínima a ocupação dos espaços midiáticos como na internet dentro dos blogs, dos jornais eletrônicos, das redes sociais e Websites. Estes meios de comunicação facilitam o desenvolvimento das estratégias de enfrentamento e empoderamento da população negra contra o racismo e suas manifestações.

Há muito que se desenvolver nesta área, por exemplo nas grandes mídias controladas pelas elites, o(a) negro(a) continua invisível processo que dificulta o reconhecimento dos mesmos dentro delas.

\section{CONSIDERAÇÕES FINAIS}

Com este estudo foi possível conhecer a opinião de alguns dos(as) militantes do Movimento Negro de Salvador sobre a imagem do(a) negro(a) transmitida pela mídia local. Bem como entrar em contato com impressões e expectativas sobre sua própria imagem na mídia e seu papel como militante negro e investigar as estratégias de enfrentamento desses(as) militantes na luta contra $\circ$ racismo na mídia de soteropolitana. 
Esta pesquisa permitiu fazer uma breve retomada na história do Movimento Negro e dos militantes, o processo de construção da visibilidade dos negros(as) nas grandes mídias e digitais e a possível influência da mesma na construção das identidades pessoais e sociais. Durante o processo de pesquisa foi possível a realização de apenas seis entrevistas sendo duas com militantes do sexo feminino. Entretanto foram encontrados resultados significativos como a constatação feita por todos os (as) entrevistados (as) sobre o reconhecimento da existência do racismo nas mídias soteropolitanas. A afirmação de que não houve influência da mídia na construção de suas identidades, foi considerado um dos aspectos que precisa ser melhor aprofundamento em futuras pesquisas. E por fim foi possível conhecer através das falas algumas estratégias para o enfrentamento do racismo e a necessidade de maior visibilidade das iniciativas já existentes, como o Observatório Negro, porém o reconhecimento que ainda são mínimos os espaços de comunicação, não existindo mudanças efetivas e significativas de combate ao racismo, por parte dos grandes veículos de comunicação.

Espera-se que o presente estudo possa estimular a ampliação e abertura de novas frentes de pesquisa da Psicologia e Relações Raciais nas mídias, para que o olhar desses veículos seja diferenciado, ético com respeito à diversidade da população brasileira contribuindo assim no combate do racismo existente.

\section{CONTRIBUIÇÕES DOS AUTORES}

Purificação T participou da concepção, delineamento, busca e análise dos dados da pesquisa, interpretação dos resultados e redação do artigo científico. Castelar $M$ participou da concepção, encaminhamentos ao comitê de ética, delineamento, coleto de dados da pesquisa, discussão dos dados, revisões da redação final do artigo.

\section{CONFLITOS DE INTERESSES}

Nenhum conflito financeiro, legal ou político envolvendo terceiros (governo, empresas e fundações privadas, etc.) foi declarado para nenhum aspecto do trabalho submetido (incluindo mas não limitandose a subvenções e financiamentos, conselho consultivo, desenho de estudo, preparação de manuscrito, análise estatística, etc).

\section{REFERÊNCIAS}

AfroPress, Agência Afro-étnica de Notícias, fundada em 2004 pela ONG ABC Sem Racismo. Recuperado de http://www.afropress.com

Alakija A. (2012). Mídia e Identidade Negra. In: Borges RCS,Borges R. (Orgs.), Mídia e racismo. Petrópolis, Rio de Janeiro: DP et Alii; Brasília, DF.

Alberti V. (2000). Indivíduo e biografia na história oral. Rio de Janeiro: CPDOC. Recuperado de http://cpdoc.fgv. $\mathrm{br} /$ producao_intelectual/arq/1525.pdf

Amaral FN. (2010). O Negro na Mídia: a construção discursiva do "outro" cultural. Recuperado de http:// www.africaeafricanidades.com/documentos/ 10082010_22.pdf

Araúio JZ. (2006). A força de um desejo - a persistência da branquitude como padrão estético audiovisual. Rev. USP, 69. Recuperado de http://www.usp.br/ revistausp/69/07-joelzito.pdf

Bacelar J. (2001). A hierarquia das raças: negros e brancos em Salvador. Rio de Janeiro: Pallas.

Baltazar B. (2004). Os encontros e desencontros da militância e da vida cotidiana. Psicologia: Teoria e Pesquisa, 20(2), 183-190.

Bardin L. (2009). Análise de conteúdo. Lisboa: Edições 70.

Bento MAS. (2002). Branqueamento e branquitude no Brasil. In: Carone I, Bento MAS. (Orgs.), Psicologia social do racismo: estudos sobre branquitude e branqueamento no Brasil. Petrópolis, Rio de Janeiro: Vozes.

Brandão NHH. (1990). Introdução à Análise do Discurso. $7^{a}$ Ed. Campinas: Editora da Unicamp.

Ciampa CA. (1997). Identidade. In LANE STM \& GODO W (Orgs.), Psicologia Social: o homem em movimento. São Paulo: Editora Brasiliense.

Cogo D, Machado S. (2010). Redes de negritude: usos das tecnologias e cidadania comunicativas de afrobrasileiros. In: XXIII Congresso Brasileiro de Ciências da Comunicação (Intercom); 2010, 1, 1-16.

Conselho Federal de Psicologia, CFP. Resolução CFP $n^{\circ}$ $018 / 2002$. Estabelece normas de atuação para todas as (os) Psicólogas (os) em relação ás questões de preconceito e discriminação racial. Brasília - DF, 19 de dezembro de 2002.

D'adesky, J. (2001). Pluralismo Étnico e Multiculturalismo: Racismo e Antirracismo no Brasil. Rio de Janeiro: Pallas; 2001. 
Freitas AMT. (2002). A abordagem sócio histórica como orientadora da pesquisa qualitativa. Recuperado de http://www.scielo.br/scielo. php?pid=S010015742002000200 002\&script $=$ sci_ arttex

Lima VA. (2004). Sete teses sobre mídia e política no Brasil. Rev. USP, São Paulo, 61. Recuperado de http:// www.revistasusp.sibi.usp.br/scielo.php? script $=$ sci_ arttext\&pid=S0103-99892004000200006\&lng=pt \&nrm=iso

Masiero AL. (2005). A Psicologia Racial no Brasil (19181929). Rev. Estudos de Psicologia. Poço de Caldas, 10(2), 199-206.

Munanga K, Gomes LN. (2006). O Negro no Brasil de hoje. São Paulo: Global.

Oliveira MI, Silva APL. (2007). Imprensa Negra Online: o racismo na pauta de todos os dias. Associação Brasileira de Pesquisadores em Jornalismo - SBPJor. Faculdade de Comunicação, Universidade de Brasília (UnB). Recuperado de http://www.afropress.com/post. asp?id=13131

Oliveira V, Ronsini MV. (2007). Ativismo negro: afirmação étnica e a reprodução do racismo na mídia. Recuperado de http://www.intercom.org.br/papers/regionais/ sul2007/resumos/R0092-1.pdf

Ramos GD. (2009). Raça identificada: a quebra da invisibilidade negra. Recuperado de http://sbpjor. kamotini.kinghost.net/sbpjor/admjor/arquivos/ daniele_gross_ramos.pdf

Santos AG. (2002). A Invenção do Ser Negro: um percurso das ideias que naturalizaram a inferioridade dos negros $\left(1^{\mathrm{a}}\right.$ Ed). Rio de Janeiro: Editora Pallas.

Silva NFI. (2001). Consciência Negra em Cartaz ( $1^{a}$ Edição). Brasília: Editora da Unb.

Vinadé FT, Guareschi PA. (2007). Inventando a contramola que resiste: um estudo sobre a militância na contemporaneidade. Psicologia \& Sociedade; 19(3):68-75; 2007. 